SISTEMA
ELETRÔNICO
DE REVISTAS
SER I UfPR

\title{
Do enfrentamento à convivência: o Fórum Seca como movimento político
}

\section{From confrontation to coexistence: the Drought Forum [Fórum Seca] as a political movement}

\author{
Shana Sampaio SIEBER ${ }^{1 *}$, Ramonildes Alves GOMES ${ }^{2}$ \\ ${ }^{1}$ Universidade Federal Rural de Pernambuco, Unidade Acadêmica de Serra Talhada, Serra Talhada, PE, Brasil. \\ ${ }^{2}$ Universidade Federal de Campina Grande, Campina Grande, PB, Brasil. \\ *E-mail de contato: shanasieber@yahoo.com.br
}

Artigo recebido em 19 de maio de 2020, versão final aceita em 27 de setembro de 2020, publicado em 18 de dezembro de 2020.

RESUMO: O presente artigo busca refletir sobre o paradigma da convivência com o semiárido a partir dos seus antecedentes históricos, evidenciados pelo Fórum Pernambucano de Enfrentamento à Problemática da Seca - Fórum Seca (1989-1996), enquanto projeto político mobilizatório anunciador de caminhos de resistência e luta. O Fórum Seca torna-se referência obrigatória na problematização da seca, sob a égide da discussão política, em ocasião do Ato Público de ocupação da Superintendência do Desenvolvimento do Nordeste - SUDENE, em março de 1993. Analisando os desdobramentos desses movimentos, direcionamos nossas lentes para o município de Serra Talhada, semiárido de Pernambuco, como lócus privilegiado de discussões; aqui, o Fórum Seca significou muito mais do que um movimento reivindicatório de ações permanentes de enfrentamento à seca, mas o embrião de um projeto político capaz de alcançar legitimidade no interior do Estado, com a noção de convivência. Para sistematizar os argumentos, nos apoiamos na pesquisa do tipo qualitativa, baseada em análise de documentos históricos e duas entrevistas semiestruturadas e individuais, que nos conduziram ao Fórum Seca. Esta colcha de narrativas possibilitou inferir que esses movimentos de enfrentamentos têm muito a ensinar ao nosso modus vivendi, convocando-nos para a defesa de conquistas históricas.

Palavras-chave: convivência com o semiárido; combate à seca; resistência; movimentos sociais; sociedade civil.

ABSTRACT: The present article reflects on the paradigm of coexistence with the semiarid based on the history that is evidenced by the Pernambucano Forum for confronting Drought -Drought Forum (1989-1996) as a political project that announces paths of resistance and struggle. The Drought Forum is a necessary reference in discussing the 
issue of drought from a political perspective in the occasion of the Public Act of occupation of the Northeast Development Superintendence-SUDENE in March, 1993. Analyzing the consequences of these movements we focus onto the city of Serra Talhada, in the semiarid of the State of Pernambuco, Brazil, as a privileged site of discussions. In this city, the Drought Forum meant much more than a movement demanding permanent actions to combat drought, but the beginning of a political project capable of legitimacy within the state through the notion of coexistence with the semiarid. The present arguments were provided by qualitative research based on the analysis of historical documents and on two semi-structured interviews which led us to the Forum. The intertwining of narratives made possible to understand that such resistance movements have a lot to teach our modus vivendi and invite us to defend historical achievements.

Keywords: coexistence with the semiarid; drought combat; resistance; social movements; civil society.

\section{Introdução}

O paradigma da convivência com o semiárido atuou fortemente na desconstrução das ideias, concepções e justificativas da seca no Nordeste, deslocando-a de uma questão física e climática para uma questão de ordem sociopolítica. De acordo com Duque (2015), a convivência configura-se em uma proposta de política pública criada e protagonizada pela sociedade civil e incorporada à agenda do Estado.

Para isso, o princípio da convivência tem sido resgatado a partir de experiências originadas de saberes populares, que são aprimorados no diálogo com o saber científico para a elaboração de um modelo diferente de política pública (Duque, 2015), capaz de desmistificar o problema da seca por meio da mudança de conceitos e culturas, que passam a constituir o esforço do governo sob o discurso da convivência (Sieber \& Gomes, 2018). Processos como estes, de acordo com Muller \& Surel (2004), são possibilitados a partir da construção de uma matriz cognitiva e normativa, produtora de identidades específicas, partilhadas por distintos atores - e relações de força-que convergem em um paradigma ou referencial com a finalidade de pautar e participar da agenda pública, governamental ou não governamental.

$\mathrm{Na}$ implementação do chamado paradigma da convivência com o semiárido, as cisternas de placas tiveram como direção o "Programa de Formação e Mobilização Social para a Convivência com o Semiárido: Um Milhão de Cisternas Rurais" (P1MC), que desde 2003 vem trabalhando com tecnologias sociais baseadas na captação e no armazenamento de água da chuva, envolvendo as famílias na compreensão do trabalho coletivo por meio da mobilização social, orientando-se pela ideia da sustentabilidade (Passador \& Passador, 2010). A partir do avanço desse referencial, a Articulação do Semiárido (ASA), em conjunto com o Ministério do Desenvolvimento Social (MDS), cria também, em 2007, o Programa Uma Terra e Duas Águas $(\mathrm{P} 1+2)$, para complementar as ações do P1MC por meio da segunda água, visando a produção agrícola e a criação de pequenos animais, integrando essas com o fomento à produção agroecológica (Amorim \& Grisa, 2018).

No entanto, o paradigma da convivência com o semiárido tem como antecedentes um intenso processo de mobilização para construir alternativas para o enfrentamento da seca, tendo como protago- 
nistas a sociedade civil mobilizada, o Movimento Sindical dos Trabalhadores Rurais, Organizações Não Governamentais, Organizações Sociais ligadas às Igrejas Cristãs, Agências de Cooperação Internacional, Associações Comunitárias, Cooperativas, Movimentos de Mulheres e Universidades, requerendo uma ação pública adequada ao semiárido frente às políticas de combate à seca (Declaração do Semiárido, 1999).

O episódio da ocupação da Superintendência do Desenvolvimento do Nordeste - SUDENE, ocorrido em março de 1993, foi um marco na história da convivência com o semiárido. Ocorrido no âmbito do Fórum Pernambucano de Enfrentamento à Problemática da Seca (Fórum Seca, 1989-1996), significou um avanço político importante para a sociedade civil, que chegava ao Estado por uma via mobilizatória reivindicando "Ações Permanentes para o Desenvolvimento do Nordeste/Semiárido Brasileiro" no Fórum Nordeste, seminário realizado em maio de 1993 nas dependências da SUDENE (Diniz \& Piraux, 2011). Aqui, as mulheres também estavam presentes e reivindicavam o alistamento nas frentes de emergência e o reconhecimento de seus direitos nos próprios sindicatos (Funari, 2016).

Na literatura que aborda a convivência, esses eventos aparecem associados às experiências dos movimentos sociais e organizações de trabalhadores rurais e suas formas de luta e resistência (Diniz \& Piraux, 2011; Diniz \& Lima, 2017), enquanto ação coletiva de mobilização social no contexto de mais uma grande seca que ocorria no semiárido nordestino, a partir de 1993 (Diniz \& Lima, 2017). De acordo com Diniz \& Lima (2017, p. 193), a intenção dessa "mobilização regional" era "influir na desestruturação e no abandono das práticas assistencialistas e clientelistas das oligarquias locais", com a elaboração de um programa de ações permanentes a ser executado pelo governo.

Nesse cenário de efervescência do Fórum Seca, o município de Serra Talhada, no sertão do estado de Pernambuco, se destacava enquanto campo de ações, sendo lócus privilegiado de discussões rumo à sistematização de conceitos que embasaram mais tarde o que se convencionou chamar de convivência com o semiárido, a partir de um Fórum que tensionou o conjunto de problemas que envolvia a seca na região.

A narrativa de combate à seca começava a ser questionada, dando lugar a uma nova forma de convivência com a seca, que se desenvolvia mediante a ressignificação do problema da seca. Só mais tarde, com o P1MC, a questão da seca vai encontrar um argumento teórico mais complexo, fazendo com que a convivência com o semiárido transpusesse a convivência com a seca, a partir de um discurso da sustentabilidade contextualizado com o bioma caatinga, absorvendo dimensões de educação, de gênero, de cidadania, de cultura, de religião e políticas (Malvezzi, 2007; Silva, 2007).

Nesse caminho, expressões como convivência, autonomia e justiça se legitimaram na "Declaração do Semiárido", documento considerado inaugural do paradigma da convivência (Cunha \& Paulino, 2014), divulgado pela Articulação do Semiárido (ASA) em 1999, no Fórum Paralelo da Sociedade Civil, durante a $3^{\text {a }}$ Conferência das Partes da Convenção de Combate à Desertificação e à Seca (COP3), dez anos depois do $1^{\circ}$ Encontro Seca, Implicações Políticas e Formas de Convivência (1989). Consolidou-se a ideia de que a seca como fenômeno natural e periódico não poderia ser combatida, mas considerada como característica própria do bioma semiárido (CONTAG, 2013). 
O Fórum Seca evidenciou uma trajetória política interessante para a reflexão, se configurando no antecedente do diálogo entre a sociedade e o Estado, marcado pelo alcance político de uma demanda da sociedade civil, fortalecido pelo contexto político da redemocratização. No constante trânsito institucional de militantes sociais-partidários por diferentes espaços de atuação, imputa-se ao paradigma da convivência uma oportunidade de se legitimar no campo político, em que o Estado se torna espaço de confluência de interesses e disputa, permeável às propostas da sociedade civil (Silva \& Oliveira, 2011; Dagnino \& Teixeira, 2014).

O presente artigo tem como pretensão trazer para a discussão o paradigma da convivência com o semiárido sob as lentes dos seus antecedentes históricos, o Fórum Pernambucano de Enfrentamento à Problemática da Seca - Fórum Seca (1989-1996), que colocou as referências para que a seca fosse problematizada politicamente, culminando no Ato Público de ocupação da Superintendência do Nordeste (SUDENE), em março de 1993. O Fórum Seca significou uma série de eventos e mobilizações de enfrentamento à seca e de críticas ao Estado, como antecedência à convivência, se destacando como campo de estudo enquanto movimento político revelador de caminhos de resistência e luta.

Para entender essa transição é preciso compreender as disputas de ideias acerca do paradigma da convivência com o semiárido, bem como quem são os atores dessas mobilizações. No intuito de nos aproximarmos desse cenário, partimos da análise de documentos históricos, tais como: a) $1^{\circ}$ Encontro Seca - Implicações Políticas e Formas de Convivência (1989); b) I Seminário Pernambucano Seca, Implicações Políticas e Formas de Enfrentamento (1990); c) Dossiê Fórum Seca. Fórum Pernambu- cano de Enfrentamento à Problemática da Seca (1991); d) Projeto Consolidação do Fórum Seca (1991); e e) Relatório Histórico do Fórum Seca, 1989 a 1996 (1997); e incorporamos aos dados a análise de duas entrevistas semiestruturadas e individuais, feitas com atores-chave: a) um dos coordenadores do Fórum Seca, sócio fundador do Centro Sabiá e professor da Universidade Federal Rural de Pernambuco, e b) um dirigente da Federação dos Trabalhadores na Agricultura do Estado de Pernambuco (FETAPE).

\section{O primeiro Encontro Seca, Implicações Políticas e Formas de Convivência}

Entre os anos de 1989 e 1996, uma diversidade de encontros, seminários, atos públicos e ocupações configuraram o que conhecemos hoje como Fórum Seca - Fórum Pernambucano de Enfrentamento à Problemática da Seca, formando as bases para desmistificar o problema da seca no Nordeste (Dossiê Fórum Seca, 1991; Relatório Histórico do Fórum Seca, 1997). O Fórum Seca representava um espaço para a articulação e a reflexão sobre as políticas de combate à seca definidas pelo Estado, que tinham vieses assistencialistas e clientelistas. Nesse campo recortado para a pesquisa, identificamos os antecedentes do paradigma da convivência com o semiárido e os atores dessa mobilização, capazes de articular diversos setores da sociedade civil, como movimentos sociais, movimentos sindicais, organizações não governamentais e academia.

Sete anos depois, não podemos dizer que a situação mudou, mas temos certeza que conhecemos limitações, e com elas a vontade de superá-las. Conhecemos a força da mobilização popular, caminhando lado a 
lado com centenas de trabalhadores rurais ou ocupando a SUDENE, para levar uma proposta de ação contra os efeitos da seca a um poder público que insiste em ignorar o sofrimento e a exploração do povo. Temos certeza da capacidade transformadora quando conseguimos unir ideias, conhecimentos, ações, na busca de um objetivo comum dentro da adversidade. Temos certeza de que o que conseguimos consolidar até hoje não foi em vão, e a sociedade civil possui uma boa referência para continuar perseguindo o sonho de ver a região prosperar sem fome, sede nem miséria (Relatório Histórico do Fórum Seca, 1997).

O Fórum Seca pretendia ser uma articulação permanente que compreendia diversas entidades de assessoria (ONGs), trabalhadores rurais, sindicatos, federação, movimentos pastorais, centros de pesquisa e intelectuais/pesquisadores empenhados na construção de alternativas para fazer frente à seca, tendo na sua coordenação a Federação dos Trabalhadores Rurais Agricultores e Agricultoras Familiares do Estado de Pernambuco (FETAPE), a Central Única dos Trabalhadores (CUT-PE), o Centro de Educação do Trabalhador Rural (CENTRU-PE), o Projeto Tecnologias Alternativas - PE/PB e o Centro de Assessoria e Apoio aos Trabalhadores e Instituições Não Governamentais Alternativas (CAATINGA) (Projeto Consolidação do Fórum Seca, 1991).

No âmbito do Fórum Seca, o I Encontro Seca - Implicações Políticas e Formas de Convivência (1989), ocorrido em Triunfo (Pernambuco) entre os dias 24 e 26 de outubro de 1989, representava o início das discussões sobre o problema da seca do Nordeste, denunciando o descaso do Estado com o atendimento das famílias rurais do semiárido. Coordenado pelo Polo Sertão Central de Pernambuco, com o apoio do PTA Centro Josué de Castro (PTA-CJC), o Encontro Seca reuniu 25 trabalhadores rurais, dois assessores do Sertão Central, um diretor da FETAPE, um técnico do Centro de Tecnologias Alternativas de Ouricuri (CTAO), um técnico do Sindicato dos Trabalhadores Rurais (STR) de Serra Talhada e dois técnicos do Projeto Tecnologias Alternativas (PTA-CJC).

\begin{abstract}
Este encontro tem como objetivo discutir e aprofundar a questão da seca no Sertão e no Nordeste. Esta será uma discussão antecipada, pois sabemos que a seca acontece constantemente, e nós não discutimos e entramos despreparados nela. Neste encontro vamos discutir esta realidade, como enfrentar uma próxima seca com opções alternativas e formas de conviver com a seca (Participante, trabalhador rural representando o Polo Sertão Central, $1^{\circ}$ Encontro Seca..., 1989, p. 02).
\end{abstract}

No polo, discutimos a necessidade de juntos aprofundarmos a questão da seca e as medidas para as soluções dos problemas. Problemas estes que jamais foram colocados pelos políticos. Sabemos que não existe uma política dos governantes para beneficiar os pequenos produtores e tirá-los das dificuldades maiores, que é a seca, feitas pelas CERCAS. Eles só fazem grandes projetos que irão beneficiar os maiores. Uma política de exportação causando a fome, a falta de terras para muitos e a concentração de terras para poucos, as doenças e tantas outras misérias, enfim, a indústria da seca (Participante, $1^{\circ}$ Encontro Seca..., 1989, p. 02).

Questionavam-se as implicações da seca e a eficácia das soluções adotadas à época, a partir da discussão de ações para combater seus efeitos e possibilitar a convivência com ela, propondo ao Estado formas diferentes para o seu enfrentamento $\left(1^{\circ}\right.$ Encontro Seca..., 1989). Os saques foram tratados como formas de resistência com história secular, ainda que outras táticas mais contemporâneas continuassem a ser adotadas: denúncias, 
passeatas, abaixo-assinados, ocupações de prédios e vias públicas, entre outros, as quais representaram a pressão dos movimentos sociais e sindicais mais combativos durante as secas.

A história de luta das mulheres foi fundamental para que os sindicatos encampassem a pauta da seca, tendo como referência suas insatisfações com as Frentes de Emergência, entre os anos de 19821983. Nesse período, uma importante liderança do movimento de mulheres para o município de Serra Talhada e região, Vanete Almeida, emergiu e ganhou destaque, enquanto assessora da FETAPE na época, se juntando a outras mulheres para elaborar um documento denunciando a exclusão das mulheres e reivindicando o seu alistamento nas Frentes de Trabalho e Emergência. Esse documento foi encaminhado à Ordem dos Advogados do Brasil (OAB), à Central Única dos Trabalhadores (CUT) e às Federações, representando uma conquista política para as mulheres (Jalil, 2013).

A inclusão de mulheres no alistamento em frentes de emergência se tornou uma espécie de referência para a visibilidade das mulheres dentro dos sindicatos e da dinâmica política da década de 1980, com destaque para o Movimento de Mulheres Trabalhadoras Rurais do Sertão Central (MMTR - SC), ligado ao Polo Sindical Sertão Central da FETAPE, no município de Serra Talhada (Bordalo, 2011). Articulada pelos sindicatos "combativos", a luta pela participação igualitária nos sindicatos impulsionaria uma oposição aos sindicatos denominados "pelegos" e transformaria a luta das mulheres em uma "política vivida", na qual as mulheres passavam a questionar, a propor e a pensar a ação do Estado (Jalil, 2013). Os sindicatos combativos seriam parceiros da demanda das mulheres, com a proposta de reorganização política menos hierarqui- zada da estrutura sindical, contribuindo para a inserção política das mulheres, ainda que por meio de mecanismos de cotas (Bordalo, 2011; Jalil, 2013).

Conforme mencionado, no $1^{\circ}$ Encontro Seca as demandas das mulheres foram incluídas na estratégia do movimento sindical, somando-se às outras formas de lutas que 14 anos depois se incorporariam à noção de convivência. De acordo com o documento:

\begin{abstract}
Nas três últimas secas, o movimento sindical passou a lutar contra toda essa injustiça, ajudando a conseguir o alistamento das mulheres e a construção de pequenas barragens, poços e açudes de interesse dos trabalhadores. As providências de combate e de convivência com a seca mais utilizadas têm sido cacimbas, cisternas, barragens, poços e artesanatos como fontes de renda para garantir a sobrevivência das famílias. (...) $\mathrm{Na}$ luta para conseguir água, os trabalhadores rurais faziam mutirão para construir poços, cacimbas e barreiras. Carregavam água de 6 a 20 quilômetros em animais, cabaças, ancoretas, latas, etc. Bebiam água de certas plantas como croatar, mucunam, coroa de frade, mandacaru, etc. Passavam muita sede e alguns eram abastecidos por carros-pipa, sendo atendidos em primeiro lugar os cabos eleitorais $\left(1^{\circ}\right.$ Encontro Seca..., 1989, p. 09).
\end{abstract}

O $1^{\circ}$ Encontro Seca representava, então, a organização de lutas históricas dos movimentos sociais e sindicais, sob os efeitos da seca de 19791984, para a construção das bases conceituais de reação política e formas de convivência.

No contexto de uma seca que perdurou cinco anos, as insatisfações dos trabalhadores e trabalhadoras rurais amadureciam frente às políticas de combate à seca. Isso incluía, além da demanda das mulheres, uma série de denúncias relacionadas à expulsão dos trabalhadores das fazendas, aos maus-tratos nas Frentes de Emergência, à desativa- 
ção do Programa de Emergência, à inadimplência do Programa de cesta básica (1983), enquanto instrumento assistencial negociado no período, e ao descumprimento dos acordos para a construção de barragens (Sieber \& Gomes, 2018).

No município de Serra Talhada, mais duas ações específicas da organização dos trabalhadores rurais lideradas pelo Sindicato dos Trabalhadores Rurais e pela FETAPE, com apoio da Igreja Católica, tiveram destaque. A luta do Travessão de Caiçarinha da Penha ${ }^{1}$ contra grandes proprietários criadores de gado e a luta dos trabalhadores rurais da Barragem de Serrinha, que configuraram a indignação popular ante as ações e omissões do governo.

O Travessão de Caiçarinha da Penha começou no final da década de 1970, culminando em uma Lei Municipal (Lei n 613/86), aprovada na Câmara Municipal de Vereadores no ano de 1986, fazendo com que a demanda dos trabalhadores chegasse no âmbito do Estado, reivindicando que se cercasse coletivamente uma área de cinco mil hectares, impedindo que o gado dos grandes proprietários destruísse as lavouras dos pequenos agricultores (Sieber, 2016).

A construção da Barragem de Serrinha (1984) foi o caso mais representativo dessa luta, gerando a indignação dos trabalhadores em torno do descumprimento do acordo firmado com o DNOCS, em 1988, desembocando paralisações no canteiro de obras da barragem - ato coordenado pelo Sindicato dos Trabalhadores Rurais e pela FETAPE. O acordo envolvia o reassentamento dos atingidos em função da construção da barragem, indenizações em atraso, ajustes de preços inadequados, etc. A primeira paralisação teve início no dia $1^{\circ}$ de junho de 1987 e foi encerrada no dia $1^{\circ}$ de julho de 1987 , contando com a participação de mais de 500 trabalhadores.

A propaganda em torno da construção da barragem era transformar o município de Serra Talhada em uma "nova Petrolina"2, com a implantação de um Projeto de Irrigação que beneficiasse produtores de gado, funcionando com serviços de abastecimento e piscicultura, com uma barragem-mãe capaz de perenizar $60 \mathrm{~km}$ do rio Pajeú. Um projeto que começou a ser planejado em 1949 pelo antigo Serviço de Estudos e Projetos do DNOCS, empregando os "flagelados da seca" a partir de 1952, tonava-se representativo da estratégia do Estado para consolidar a "indústria da seca", em resposta ao cenário de calamidade provocado pela seca (Sieber, 2016).

Assim, a década de 1980 representou a frutificação de diversas formas de reivindicações e mobilizações que confrontavam as políticas de combate à seca, se materializando em Encontros e Seminários, os quais compreenderam o Fórum Seca como um audacioso programa de ações permanentes de "convivência". Por meio de "tecnologias alternativas"

\footnotetext{
1 Segundo Abreu e Lima (2003), conflitos semelhantes atingiam outras regiões, em que foram conquistados Travessões nos municípios de São José do Belmonte e Flores.

2 A expressão "nova Petrolina” é utilizada pela Secretaria de Agricultura Familiar do município de Serra Talhada com sentido metafórico em relação à agricultura irrigada praticada nos perímetros irrigados dos polos dinâmicos da região de Juazeiro e Petrolina.

3 As tecnologias alternativas eram o foco do Projeto Tecnologias Alternativas, que tem origem na FASE (Federação de Órgãos para Assistência Social e Educação), no Rio de Janeiro, e foi responsável pela difusão dos princípios da Tecnologia Apropriada como opção para a superação da pobreza rural no Brasil, a partir da realização de um mapeamento das experiências de resistência à modernização existentes no interior dos estados do Nordeste. Com origem em um ato "político" materializado na organização de um seminário ocorrido no município de Campinas, no final de 1983, o PTA recebeu influência do economista alemão Ernst Friedrich Schumacher, com sua publicação O negócio é ser pequeno (Silva, 2011).
} 
capazes de desmistificar o problema da seca no sertão, o sentido da convivência se estruturava em uma nova forma de organização e planejamento, que começava a ser entendida como problema político:

A nivel da história do Polo, é a primeira vez que sentamos num periodo que não é de seca para discutir sobre a seca, onde vamos discutir a história e começarmos a discutir sobre as formas de convivência, onde sabemos que o problema não é apenas uma seca, mas sim a Política Agrícola, cerca, falta de preço para os nossos produtos, ou seja, é um problema realmente político, e os trabalhadores com este encontro vai dar um salto grande em qualidade, pois não devemos lutar por comida apenas quando estamos com fome (Participante, $1^{\circ}$ Encontro Seca..., 1989, p. 03).

A narrativa evidencia a construção de outro modus operandi no tratamento da seca, demandando políticas voltadas para o Nordeste semiárido. A seca, agora vista como um fenômeno social e político, ocuparia a centralidade da organização e da mobilização dos agricultores e seu enfrentamento deveria ser responsabilidade dos governantes - enfoque que pouco a pouco se distanciava da visão da seca como problema meramente climático.

A seca também parte de nossa desorganização, quando vendemos todos os nossos produtos baratos e vamos comprar coisas, isso provoca a seca. Não vamos discutir só a seca de estiagem, pois isso não podemos combater, mas sim, a seca provocada pela falta de responsabilidade dos nossos governantes (Participante, $1^{\circ}$ Encontro Seca..., 1989, p. 03).

Paralelamente, eram estabelecidos vínculos entre a situação fundiária e a questão social. Os grandes proprietários eram vistos como principais beneficiados das políticas de combate à seca. Uma luta de classes alimentava o discurso de oposição, entre os trabalhadores rurais sem terra e sem acesso à água, que trabalhavam para os grandes proprietários, e os latifundiários, coronéis ou políticos que se capitalizavam às custas dos processos oriundos da seca, favorecendo os seus interesses eleitorais $\left(1^{\circ}\right.$ Encontro Seca..., 1989). Aqui, conviver e combater a seca enquanto forma de resistência implicaria:

- Fazer reuniões na comunidade explicando o que é a seca e fazer reivindicações de construções de barragens;

- Estudar o que pode ser feito usando os recursos existentes na comunidade, tais como: construção de Casas de Farinha Comunitárias, hortas, etc.;

- Informar os perigos e os meios que os trabalhadores têm para superar os problemas com a seca, explicando todas as formas alternativas possíveis;

- Discutir a produção e as tecnologias alternativas, fazendo propostas políticas para amenizar o problema da seca;

- Os Sindicatos, junto às comunidades, devem discutir a problemática do roçado e da criação de animais;

- Lutar por um Governo Municipal, Estadual e Federal comprometido com os trabalhadores;

- Procurar conhecer as plantas resistentes à seca para servirem de alimentação aos trabalhadores e aos seus animais, fazendo plantios comunitários;

- Organizar-se para exigir poços comunitários equipados com profundidades de acordo com as condições dos terrenos;

- Exigir o pagamento dos trabalhadores de forma organizada e que o dinheiro seja administrado através de um conselho, onde a comunidade deve ficar ciente de que deve utilizar melhor este dinheiro do governo, dinheiro do povo;

- Os sindicatos têm que aproveitar os meios de comunicação para divulgarem as secas previstas, historiando as anteriores com documentos, antecipando as propostas com documentos e encaminhando às autoridades competentes;

- Os sindicatos, junto às entidades comprometidas com os pequenos produtores, devem informar, an- 
tecipadamente, através de cartilhas, cursos e treinamentos, ou outras iniciativas. ( $1^{\circ}$ Encontro Seca..., 1989, p. 11-13).

\section{O I Seminário Pernambucano, Seca: Implicações Políticas e Formas de Enfrentamento}

Na década de 1990 outro encontro foi organizado para discutir a questão da seca no Estado de Pernambuco: o I Seminário Pernambucano, Seca: Implicações Políticas e Formas de Enfrentamento. Organizado pelo Projeto Tecnologias Alternativas do Centro Josué de Castro e pelo Polo Sindical de Serra Talhada, o Seminário envolveu outras entidades ainda não citadas neste processo: a Comissão Pastoral da Terra, o Grupo de Ecologia Humana da Universidade Federal Rural de Pernambuco (UFRPE) e a OXFAM, organização inglesa de financiamento aos povos do terceiro mundo, no período de 27 a 30 de agosto de 1990, em Camaragibe (PE).

$\mathrm{O}$ encontro pretendeu desenvolver iniciativas para o entendimento da seca e a sistematização de orientações, envolvendo as organizações dos trabalhadores rurais e suas assessorias, definindo formas de atuação conjunta e alternativas técnicas de combate às causas e efeitos da seca. Durante o Seminário, os participantes concluíram que o interesse do governo era mais complexo do que a obtenção de vantagens com a seca, caracterizan- do-se pela manutenção da dominação e da miséria no campo, por meio de políticas assistencialistas que estimulavam o comodismo e a dependência, desarticulando a luta por direitos.

A necessidade da organização dos trabalhadores aparece entrelaçada em suas propostas, o que fica explícito no relatório do I Seminário Pernambucano, Seca: Implicações Políticas e Formas de Enfrentamento, no texto-resumo da exposição de Manoel Santos ${ }^{4}$, um dos coordenadores do Fórum Seca e sindicalista destacado no município de Serra Talhada. Para Manoel Santos, a demanda por alimentos precisava ser questionada, uma vez que estava associada a abusos políticos em torno da questão da fome e da seca, reproduzindo a subordinação dos trabalhadores. O texto identificava a necessidade de mudança de orientação:

Nesse momento, começamos a ver a necessidade de mudar de tática, porque ações como a distribuição de alimentos abafam a real situação dos trabalhadores. Discutimos com os próprios trabalhadores e mostramos que não iríamos procurar o Prefeito para distribuir alimentos, porque queríamos que houvesse uma decisão politica de reconhecer a situação de miséria que estavam passando os trabalhadores. Então, passamos a batalhar junto ao Governo do Estado; fomos a Brasilia e tivemos uma audiencia com o Ministro da Agricultura. O que temos observado em todo esse processo é que, do ponto de vista político, a fome e a seca interessam para os políticos. Não há interesse deles em resolver os problemas dos trabalhadores, porque quanto mais o homem passa

\footnotetext{
4 Manoel Santos foi agricultor familiar e iniciou o seu trabalho nos movimentos sociais como Agente Pastoral da Ação Católica Rural (ACR), entre 1973 e 1978, filiando-se ao Sindicato dos Trabalhadores Rurais de Serra Talhada (SRT). Atuou na Federação dos Trabalhadores da Agricultura do Estado de Pernambuco (FETAPE), na Confederação Nacional dos Trabalhadores na Agricultura - CONTAG, na Central Única dos Trabalhadores - CUT - e no Partido dos Trabalhadores - PT - em Pernambuco. Eleito deputado estadual pelo Partido dos Trabalhadores - PT, Manoel Santos faleceu em meados de 2015. (Assembleia Legislativa de Pernambuco. Disponível em: <http://www.alepe.pe.gov.br/ paginas/?id=3576>. Acesso em: jun. 2015).
} 
fome, mais será subordinado politicamente, será enganado com um pequeno beneficio, que o leva a votar no candidato daquele que o engana. O homem com fome não tem condições de pensar (Dirigente Sindical Manoel Santos, I Seminário Pernambucano, Seca..., Relatório, 1990, p. 19).

O interesse político na fome e o uso político da distribuição de alimentos é denunciado pelo sindicalista enquanto prática das políticas de combate à seca. A "fixação" do trabalhador no campo é problematizada como parte da alternativa para a reivindicação de um programa governamental federal e estadual capaz de proporcionar a desapropriação de terras e a reforma agrária, ampliando as condições para o trabalhador produzir com o direito de continuar na agricultura.

\section{PROPOSTAS DO MOVIMENTO SINDICAL}

Em primeiro lugar, nossa reivindicação é que o trabalhador que não tem terra seja atendido dentro de um programa que vise sua fixação no campo. Que o governo desaproprie as áreas que podem ser usadas com irrigação e que coloque esses trabalhadores em condições de produzir. A seca é um problema que também está diretamente ligado à questão da reforma agrária. Para o trabalhador que já tem terra, defendemos a realização de um programa que, ao invés de tirar o homem de onde ele está produzindo culturas e criando animais para construir açudes e estradas, garanta a esse homem o direito de continuar na sua agricultura. Quanto aos trabalhadores de periferia das cidades, nossa proposta é realizar mutirões de produção de tijolos e construção de suas casas, respondendo ao débito do governo no campo da moradia. Entendemos que esse programa precisaria da intervenção do Governo Federal, no aspecto político e dos recursos, e a sua coordenação deveria ser feita através do Governo do Estado. Por quê? Porque tendo uma coordenação no Estado, a gente sabe a quem cobrar, a quem denunciar, a quem exigir (Dirigente Sindical Manoel Santos, I Seminário Pernambucano, Seca..., Relatório, 1990, p. 20).

Com este formato teríamos o embrião de um diálogo com o Estado, sob uma coordenação estadual, com a continuidade da resistência por parte dos sindicatos, capaz de cobrar, denunciar e exigir. De uma crítica às ações do governo federal, farta de denúncias e reivindicações, a demanda dos trabalhadores começava a se constituir em um movimento político de desconstrução do discurso da seca no semiárido.

Nesse sentido, o problema da seca era questionado e compreendido por uma dimensão política que começava a se desenvolver sob um caráter polissêmico, de acordo com Muller \& Surel (2004): no desenvolvimento do debate partidário (politics) e no diálogo entre a sociedade civil e o Estado (polity), requerendo políticas públicas e programas governamentais (policies). Assim, sob uma nova forma de tratar a seca, expurgavam-se as práticas de aproveitamento eleitoral, instrumentalizando os sindicatos para a luta e a articulação dos trabalhadores, reivindicando um Programa Permanente de combate aos efeitos da seca ${ }^{5}$ no seio dos movimentos sindicais, como essência constitutiva do paradigma que estava por vir. Como resultado do Seminário, uma carta endereçada ao Banco Mundial e à sociedade civil foi redigida, intitulada "Por Terra e Vida no Semiárido". Destacamos um trecho das suas propostas a seguir:

\footnotetext{
5 Diante das nossas observações, este Programa Permanente teria sido reformulado em 1993 e ganhado neste período maior legitimação com a elaboração do documento propondo "Ações Permanentes para o Desenvolvimento do Nordeste Semiárido Brasileiro: Propostas da Sociedade Civil”, oriundo do Fórum Nordeste (Diniz, 2007).
} 
Queremos um PROGRAMA PERMANENTE DE COMBATE AOS EFEITOS DA SECA, elaborado conjuntamente com a sociedade civil, através de suas organizações, e que procure preparar a população para enfrentar a seca, enquanto situação particular do ecossistema nordestino, e não como um tempo de fome, miséria e subordinação. Que o Estado tenha programas de emergência necessários em momentos imprevisíveis de calamidade, tais como ocorre nas inundações. (...) Seca não deve ser discutida somente nos períodos em que este fenômeno ocorre. Para isto nos propomos a CONSTRUIR O FÓRUM AMPLIADO DE ENFRENTAMENTO DA PROBLEMÁTICA DA SECA DE PERNAMBUCO, a ser constituído por entidades sindicais, de assessoria, de pesquisa, ambientalistas, ecologistas, partidos políticos e sociedade civil. O mesmo terá a função de fazer com que a problemática da seca faça parte do dia a dia da sociedade, de forma tão normal como um dia de sol ou um dia de chuva (I Seminário Pernambucano, Seca..., Relatório, 1990, p. 21).

\section{O protagonismo do Fórum Seca e suas formas de enfrentamento}

O Fórum Seca consistiu em um espaço ampliado de enfrentamento ao problema da seca, cuja materialidade implicava em articular diversas entidades de assessoria (ONGs) e associações de trabalhadores rurais, sindicatos, movimentos pastorais, centros de pesquisa e pesquisadores. Nesse contexto, o I Encontro Seca: Implicações Políticas e Formas de Convivência (1989) significou o ponto de partida para o seu surgimento, em um espaço que pretendia discutir a seca de forma planejada, anterior à sua ocorrência - 1990 a 1993. Para um Fórum que teve sete anos de existência (1989 a 1997), o esforço dos atores era a construção de uma articulação estadual para enfrentamento permanente dos problemas e crises que decorrem da seca. Com o Relatório Histórico do Fórum Seca, visualizamos as principais ações que nortearam sua articulação com instituições e organizações da sociedade civil nos níveis regional e nacional, sistematizadas em 30 eventos para a formulação de um novo modelo de desenvolvimento capaz de encerrar o drama da população do semiárido e de toda a região Nordeste.

Para a sistematização do Fórum Seca, foi elaborado um dossiê com o objetivo de registrar as primeiras ações e iniciativas do que pretendia ser uma "nova história" de enfrentamento, comprometida com a emancipação dos trabalhadores rurais do Nordeste. Foram reunidos textos e trechos de jornais publicados durante o Fórum (Dossiê Fórum Seca, 1991).

No I Seminário, a proposta era trazer para o debate ecologistas e pesquisadores de Universidades Federais e da própria SUDENE, representando mais um passo significativo para o entendimento da seca e a definição das formas de atuação, configurando um formato epistemológico que pretendia desmistificar o problema e denunciar o descaso do Estado. O Fórum Pernambucano pretendia analisar a seca em seus aspectos climáticos, sociais, políticos e econômicos, qualificando-a como um problema que tem solução, pautada por ações eficazes, voltadas aos trabalhadores (Dossiê Fórum Seca, 1991).

Com o Fórum Seca em cena, e as mobilizações que decorreram dele, o debate sobre a seca se desenvolvia como contraponto aos programas assistenciais, construindo sua crítica mais avançada ao programa de cestas básicas do Governo Federal, a partir de uma avaliação política e nutricional. A cesta básica anunciada pelo governo se referia à distribuição de uma cesta alimentar mensal, destinada a famílias de oito pessoas, contendo dez $\mathrm{kg}$ de arroz, três $\mathrm{kg}$ de farinha e três $\mathrm{kg}$ de fubá de 
milho. A análise foi conduzida por Manoel Santos, dirigente da FETAPE; Emília Perez, nutricionista da Universidade Federal Rural de Pernambuco; e Reginaldo Muniz, economista do DIEESE, que participaram como palestrantes, e foi coordenada pelo jornalista Fernando Velozo e pelo pesquisador Marcos Figueiredo.

Segundo a nutricionista Emília Perez, a cesta básica oferecida pelo Governo Federal traz consequências danosas para as famílias carentes: "Uma alimentação sem leite, peixe, carne ou determinados cereais impede o crescimento das crianças, lesando, principalmente, o seu cérebro e o seu coração e impedindo os adultos de desenvolverem suas atividades físicas e intelectuais - o trabalho", ensina a nutricionista. Ela diz que, fazendo um cálculo, por integrante de família, "a cesta Collor não chega a oferecer 250 calorias, quando uma pessoa necessita de 1.700 a 3.000 calorias por dia. Enquanto são necessários, diariamente, 40 a 70 gramas de calorias, essa cesta não chega a garantir cinco gramas diárias ao trabalhador da região da seca". (...) A intervenção do Governo Federal com essa "cesta trágica", segundo Manoel Santos, "é para matar de fome se for viver só com estes produtos". Com isso, disse ele, o Governo deixa o povo e suas organizações atônitos e imobilizados; não abre as frentes de emergência, criando uma imagem de bom governo para quem está desinformado sobre a realidade; e reforça as suas bases políticas nos municípios. Essa política é realmente nova, reciclada e aprimorada para desestruturar o que já existe em nível de organização autônoma dos trabalhadores e, também, no aspecto das ações do Governo Estadual, visto que Collor desconsidera a existência do Poder Municipal (Dossiê Fórum Seca, 1991, n.p.).

Com a organização do Fórum, a sistematização das contribuições dos pesquisadores serviu de base conceitual para fortalecer a crítica dos movimentos, construindo alternativas para o problema da seca ante ao Estado. De um lado se consolidava a organização dos trabalhadores, em torno do movimento sindical e das assessorias populares, recebendo apoio de pesquisadores. E, de outro lado, tinha continuidade a "indústria da seca", associada às intervenções do Estado (federal, estadual e municipal) que reproduziam a dependência dos agricultores aos políticos fisiológicos (Projeto Consolidação do Fórum Seca, 1991).

O Fórum teve presença mais expressiva no Ato do seu lançamento, no dia cinco de maio de 1991, no município de Serra Talhada, possibilitando a mobilização de cerca de 10 mil agricultores de 33 municípios - do Sertão do Araripe, Sertão de Petrolina, Sertão Central, Sertão do Pajeú, Sertão do São Francisco, Agreste e Mata, região da Zona Canavieira - que reivindicavam políticas compatíveis com o semiárido e com as necessidades dos pequenos produtores. Neste momento, o Fórum Seca já teria suas bases políticas mais sedimentadas, contrapondo-se a todo o discurso da seca baseado em migalhas assistencialistas e politiqueiras que, até então, têm contribuído para a ascensão de políticos e latifundiários (Projeto Consolidação do Fórum Seca, 1991). Não foi por acaso que o Ato público de Lançamento do Fórum Seca aconteceu no município de Serra Talhada, o "coração do sertão", manifestando-se por uma lógica de articulação que inaugurava um espaço público não estatal na construção de um projeto político, em oposição à lógica do Governo Federal, tal como afirma o Coordenador do Fórum:

O Fórum Seca foi em Serra Talhada porque Fernando Collor quando ganhou as eleições, no auge das secas nos anos 90, ele ganhou de Lula nas eleições. Ele tomou posse e foi pra Serra Talhada ver a seca e ele fez um discurso lá, prometendo uma série de politicas para o semiárido, utilizando umas expressões de bai- 
xo calão e tal, e nós quando organizamos o FORUM SECA nós pensamos em fazer o Ato em Serra Talhada exatamente pra contrapor a lógica de politicas que Fernando Collor de Melo tava prometendo. Então nós tivemos todo um trabalho de Articulação com o assessor de Lula, né, que morava aqui em Pernambuco na época, pra que ele viabilizasse a participação de Lula nesse ato. Lula tinha sido candidato derrotado, era o nosso candidato e ele poderia muito bem expressar esse pensamento nosso, e ai nós fizemos isso. Depois nós fizemos dois seminários grandes aqui em Pernambuco com o Governo Paralelo. Que foi aquele governo que Lula criou quando ele perdeu as eleições pra Collor, ele criou vários ministérios e criou um Governo Paralelo. Nós fizemos aqui dois seminários, "Seca, desafio e perspectiva". É, eu acho que esse foi um dos seminários que fizemos. (...) Eu acho que só isso aí já merecia uma reflexão mais aprofundada, porque eu acho que é uma coisa que naquele momento assim, colocava um contraponto a toda política hídrica do DNOCS e da SUDENE pra região, entendeu? Então, eu acho que a análise política do Fórum Seca ela precisa ser retomada e mais aprofundada, e ninguém fez ainda porque eu acho que ela inaugura um debate político com a sociedade civil, no sentido de que é possível alternativas que venham da própria sociedade civil. O próprio Lula num discurso que fez lá em Serra Talhada ele conclamou, né, os Sindicatos, conclamou a Federação, conclamou a CONTAG, alguns movimentos sociais, que organizassem um FORUM SECA em cada Estado, né. É tanto que surgiu um no Rio Grande do Norte, um chamado FORCAMPO, né, surgiu... A Articulação do Semiárido da Paraiba ela surge exatamente depois do Fórum Seca. A Articulação do Semiárido da Paraíba, que é o mesmo nome que vai dar pra Articulação do Semiárido, só que a da Paraíba é mais antiga (Coordenador do Fórum Seca, Sócio fundador do Centro Sabiá e Professor da UFRPE, entrevista realizada em fevereiro de 2015).

A conjuntura política em que se desdobrava o Fórum Seca tinha como pano de fundo as eleições de 1989, a primeira eleição direta para Presidente da República do Brasil após o regime militar. Com a organização do Fórum Seca, lançado no município de Serra Talhada, consolida-se o potencial do movimento para se contrapor ao modus operandi das políticas tradicionais, gestando-se as bases conceituais para uma mudança de paradigma, para uma nova forma de enfrentamento da questão da seca e das autoridades competentes, com suas políticas voltadas para a grande propriedade. A disputa partidária travada nesse momento tinha como referência o município de Serra Talhada, possivelmente em consequência de sua trajetória mobilizatória frente às políticas de combate à seca, com casos de saques e paralisações nas frentes de emergência. Após a visita do Presidente Fernando Collor (PRN) ao município, divulgando mais um Programa de Cestas Básicas para a população desassistida, a presença do candidato derrotado, Luís Inácio Lula da Silva (PT), no palanque do Ato de lançamento do Fórum Seca deixava evidente o potencial do Fórum Seca para a construção de um movimento político, apoiado pela Igreja e pela sociedade civil.

Essa questão pode ser melhor compreendida pela análise dos discursos públicos, por meio da contribuição teórica de Pierre Bourdieu (2014), implicitamente no processo de formação dos sindicatos e na organização dos trabalhadores, em que, por vezes encontramos a palavra profética, materializada na forma de ideal coletivo proveniente da Igreja, que trazia o "melhor" conforme as exigências e visões de mundo do grupo sobre si mesmo. A seca como problema no Nordeste não mais se assemelha à imagem de castigo de Deus, sendo traduzida por teses de como conviver com a seca e buscar estratégias para continuar vivendo no Nordeste, tendo o Fórum Seca como iniciativa protagonizada pela 
sociedade civil. A seguir, destacamos trechos do Dossiê Fórum Seca sobre este aspecto:

Mas, o que nós queremos é que o Fórum promova estudo sério sobre como conviver com a seca. Ninguém pode impedir a seca, a seca é um fenômeno natural. Mas a gente pode estudar, pesquisar, pensar, experimentar e chegar a encontrar meios. Meios não utópicos, não sonhos, mas sonhos reais, e a gente poder viver na nossa terra querida e amada desse Nordeste, flagelado da seca, mas sempre amado por cada um de nós. (...) É a possibilidade que a sociedade brasileira tem de criar algo sério, capaz de enfrentar uma discussão nacional sobre o problema da seca, visando resolver de forma definitiva o problema da seca no Nordeste. O Fórum Seca pode tocar nessas coisas e pode, a partir de agora, mostrar pra sociedade brasileira que existe um Fórum, que não é uma coisa do Estado, não é uma entidade governamental, não está a fim de viver do dinheiro do Estado, mas é uma entidade civil representada por vários segmentos da sociedade, que está disposta a levar a questão da seca mais a sério do que já foi levada até hoje no Brasil. (...) Nós não podemos terminar o século deixando o povo aceitar a ideia de que ele é miserável porque Deus quer, ou que está com fome porque Deus quer, que existe a seca porque Deus quer. Não podemos mais deixar o povo ficar acreditando nisso, se nós quisermos ajudar o povo. E o Fórum, como não é de partido político, não é de um sindicato, mas de diversos segmentos da sociedade, pode contribuir de forma decisiva para que a gente dê outra dimensão a discussão da seca no Nordeste brasileiro. O Fórum é um início de um movimento que pode envolver muita gente, desde partidos políticos, Igreja, até sindicatos e toda a sociedade civil (Dossiê Fórum Seca, 1991, n.p).

O Fórum possuía também um caráter epistemológico acerca da seca, trazendo o apoio das pesquisas científicas na construção do novo paradigma que se desenvolveria, a partir da noção da "convivência com a seca". Marcado por um desinteresse à coisa do Estado, que torna subliminar o interesse tácito em dominá-lo, a sociedade civil passa agora a existir para levar a questão da seca como uma discussão política, ainda com a ideia de um público não estatal de força política em oposição a um Governo específico. Com este formato, a ideia de um público não estatal seria experimentada, na busca de um diálogo capaz de superar a noção de uma sociedade civil de costas para o Estado, mediante a progressiva construção de canais de participação e a ampliação do campo da sociedade civil (Gohn, 2013).

O Fórum Seca realizou uma série de reuniões, encontros, seminários e atos públicos para sua articulação estadual, que teve na ocupação da SUDENE pelos trabalhadores rurais, em março de 1993, sua principal referência, conformando-se em uma grande mobilização regional, a qual exigiu que os governos federais e estaduais tomassem providências em relação à seca.

Nosso primeiro marco talvez tenha sido a criação do Fórum Seca no final dos anos 80, começo dos anos 90, que era uma junção das organizações que trabalhavam no campo pra discutir formas de conviver com o semiárido. E essa forma, sobretudo, veio criar um tema mais forte e talvez seja um marco nessa questão da discussão da convivência com o semiárido, foi o ano de 93, tem um ano histórico que foi quando nós tivemos longas secas, muito dificeis e que os trabalhadores resolveram enfrentar, e foi um periodo em pleno periodo de transição democrática federal e que nada foi exposto para ajudar os agricultores que tavam na situação de fome e de miséria muito grande. E foi quando o movimento sindical decidiu aqui em Serra Talhada, numa reunião em Serra, resolveu fazer o acampamento na SUDENE, então atacar uma entidade federal, atacar no bom sentido, né, de enfrentar para que ela assumisse o seu papel. Se a SUDENE tinha, foi criada com o objetivo de fazer o desenvolvimento no Nordeste, como era que 
essa instituição não tinha nenhuma política voltada para agricultura familiar e para a convivência com o semiárido? Todos os nossos projetos eram projetos de indústrias ou de grandes agroindústrias. E foi lá que a gente, que os trabalhadores foram pra frente da SUDENE num grande ato em março de 93 (Dirigente da FETAPE de Serra Talhada, entrevista realizada em maio de 2015).

Nesse momento, as formas de enfrentamento construídas ao longo dos sete anos de existência do Fórum Seca, e todas as lutas travadas anteriormente, especialmente na década de 1980, demarcaram esforços de resistência; todavia, necessitavam de uma ação mais concreta e propositiva, fato que se dá pela ocupação da SUDENE, sobretudo enquanto emergência de uma "ação coletiva" que vai compor a noção da convivência com o semiárido, conforme destacam Diniz \& Lima (2017).

O ato da ocupação da SUDENE não foi uma ação pontual, ocorrida no dia 16 de março de 1993; envolveu uma complexidade de ações, encontros e outras ocupações, pensadas no âmbito do Fórum Seca, que desembocaram na construção de um Plano Permanente de Ações para o Semiárido. Nesse sentido, foram realizados mais dois Seminários, um estadual e outro regional, para a sua sistematização. O Seminário Estadual do Plano de Ações Permanentes foi realizado nos dias 29 e 30 de abril de 1993, no Retiro dos Padres, em Olinda (PE), onde a proposta da sociedade civil foi elaborada; essa proposta foi sistematizada no Seminário Regional do Plano de Ações Permanentes, ocorrido entre 10 e 13 e maio de 1993 no Centro de Treinamento da SUDENE - CETREINO. Coordenado pelo Fórum Nordeste, este espaço iria reunir o conjunto de propostas discutidas nos Seminários Estaduais de vários Estados do Nordeste para compor um Plano de Ações Permanentes da Sociedade Civil (Relatório Histórico do Fórum Seca, 1997).

Com o Fórum Nordeste, legitimava-se o "gérmen" para a constituição de espaços coletivos de discussão sobre a convivência com o semiárido, iniciada a partir do Fórum Seca, por meio da concretização da proposta de "Ações Permanentes para o Desenvolvimento do Nordeste/Semiárido Brasileiro" (Assis, 2012), documento que sugere a discussão democrática de políticas públicas pautadas pela questão do desenvolvimento sustentável na região, executadas pelo Governo Federal (Fórum Nordeste, 1993; Duque, 2008).

É importante perceber a contribuição da Confederação Nacional dos Trabalhadores na Agricultura (CONTAG) na organização das caravanas de trabalhadores rurais de todos os Estados do Nordeste, com destaque para a caravana do Estado de Pernambuco, que contou com o apoio de diversas entidades e lideranças sindicais rurais nesse contexto da ocupação. Tendo reunido em torno de 400 trabalhadores rurais, orientados pelo Fórum Seca e pela CONTAG, a ocupação da SUDENE é descrita por um dos coordenadores da ação de forma mais detalhada, contextualizando o diálogo com o superintendente da SUDENE.

E aí nós juntamos um grupo grande de trabalhado-
res vindo do Rio Grande do Norte, da Paraíba e de
Pernambuco e fizemos um ato em frente à SUDENE.
E entramos na SUDENE, em torno de 50 trabalha-
dores além de alguns assessores do Fórum Seca. E
nas discussões que a gente fazia dentro do auditó-
rio da SUDENE nós decidimos ter uma audiência
com Cassio Cunha Lima, que era Superintendente
da SUDENE. Nessa audiência, a gente colocou a
situação, de desmando do governo, de desleixo, e
aí ficou uma situação que Cassio não podia dar res-
posta, tava esperando resposta de Brasília pra ver 
o que é que podia fazer, o que não fazia, então nós convidamos... ele a ficar conosco na SUDENE. (...) Então ai ocupamos, ficamos lá, Cassio ficou com a gente e ficamos lá dormindo na SUDENE, passamos o dia, Itamar Franco disse que queria negociar e convidou uma Comissão a ir a Brasília. (...) Quando chegamos lá em Brasilia quem nos recebeu não foi Cassio, foi Fernando Henrique Cardoso, ele era Ministro da Fazenda de Itamar Franco e nós fizemos um trabalho de mobilização com os parlamentares, né, parlamentares de Pernambuco, da Bahia, pra estar na audiência. E nesse momento é... Manoel Santos que era secretário geral da FETAPE, não era presidente ainda. Ele fez uma fala, outras pessoas fizeram uma fala e FHC ele sinalizou com resposta que era pro governo, a partir daquele momento, o Ministério da Fazenda ia colocar uma verba de 100 milhões de reais por mês para atender uma proposta elaborada por nós. Foi aí quando nós fizemos o Plano Permanente de Ações para o Semiárido (Coordenador do Fórum Seca, sócio fundador do Centro Sabiá e Professor da UFRPE, entrevista realizada em fevereiro de 2015).

O Plano de Ações Permanentes elaborado sob a liderança da CONTAG foi apresentado ao Presidente Itamar Franco (PMDB) em consequência de uma negociação positiva, que significou para o movimento o primeiro passo de uma ação concreta, favorecida pela janela de oportunidades que se abriu após o impeachment do Presidente Fernando Collor, em 1992. Nesse momento, as pequenas obras colocadas em pauta pelo Fórum Seca poderiam ser levadas a efeito, com a transição das Frentes de Emergência para as Frentes Produtivas, no sentido de tornar o semiárido viável do ponto de vista produtivo para o pequeno agricultor.

Se o Fórum Seca conseguiu consolidar durante sete anos um espaço de articulação de âmbito estadual capaz de mediar ações significativas para o que se tem hoje sistematizado como convivência com o semiárido, a força da mobilização popular em cena desde a década de 1980 possibilitou isso (com a influência da Igreja nos processos de organização sindical), com destaque para a trajetória dos movimentos sindicais de Pernambuco.

Enquanto projeto político, essas formas de luta e enfrentamento desenvolvidas no âmbito do Fórum Seca parecem ser cada vez mais exemplares, frente aos desdobramentos das conjunturas políticas atuais na prática da convivência com o semiárido. A noção de "projeto político" se desenvolve no vínculo entre cultura e política, expressando-se na veiculação e na produção de significados que integram matrizes culturais mais amplas, sem se reduzir a estratégias de atuação política no sentido estrito. Diz respeito a uma concepção gramsciana que pretende designar os conjuntos de crenças, interesses e concepções de mundo do que deve ser a vida em sociedade, que orientam a ação política dos diferentes sujeitos (Dagnino, 2004).

\section{Considerações finais}

O Fórum Seca se constituiu enquanto articulação de um projeto político para a construção do paradigma da convivência com o semiárido. Gestado da mobilização dos trabalhadores e trabalhadoras rurais em suas estratégias de luta e resistência, sob a hegemonia de diversas formas de dominação - do regime militar e das políticas de combate à seca -, um projeto político democratizante amadurecia, fundado na ampliação da cidadania e na participação da sociedade civil, de acordo com Evelina Dagnino (2004), capaz de constituir um campo de disputa.

Ao longo do processo de redemocratização do país, um contendor legitimado com base no 
fortalecimento da sociedade civil se manifestava, encontrando suporte significativo na Constituição de 1988, com a criação de novos espaços participativos representados na conjuntura do Fórum Seca. Neste período, histórias de enfrentamento se desenvolveram, no sentido de desmistificar o problema da seca no Nordeste a partir do fortalecimento e da organização da sociedade civil, planejando uma discussão antecipada sobre a seca na direção de uma política voltada para o semiárido.

Assim, o Fórum Pernambucano de Enfrentamento à Problemática da Seca foi anunciador de um modus operandi de resistência e luta, embrionário de um projeto político mobilizador, capaz de alcançar legitimidade no interior do Estado, com a noção de convivência, e fazer da questão da seca um problema muito mais político do que climático. No entanto, a trajetória de enfrentamento ainda tem um longo caminho a percorrer, principalmente no sentido da produção de uma crença que a seca é contingente e, portanto, a ação pública precisa considerar as especificidades do bioma caatinga e o semiárido na sua totalidade e perenidade.

Na medida em que o campo político é conquistado em suas diversas formas, há uma trajetória de luta da sociedade civil no processo de disputa, que encontra no Estado um meio para sua oficialização. O que está em jogo no campo político é o monopólio da capacidade de fazer ver e de fazer crer em um embate de ideias e poderes, que podem se tornar políticas e ideias-força ainda mais hegemônicas se associadas a uma aprovação religiosa (Bourdieu, 2000).

A iniciativa do Fórum Seca foi pioneira, sobretudo para o protagonismo de um discurso de convivência com a seca, revelador da urgência de inverter a crença da seca como problema, para a seca como ator integrante da paisagem do semiárido. Sem nenhuma pretensão de apresentar argumentos conclusivos, a efetividade da luta que foi encabeçada pelo Fórum Seca ainda no final do século XX possibilitou o desvelamento de problemas sociopolíticos e criou alternativas de modernização, representativas do que se conhece hoje como "tecnologias sociais". De igual importância se destaca o incentivo à organização social, que contribui substantivamente para o empoderamento dos grupos mais espoliados e transforma a imagem da seca, fazendo que esta deixe de ser um problema e passe a ser um meio de convivência política.

\section{Agradecimentos}

Agradecemos à Coordenação de Aperfeiçoamento de Pessoal de Nível Superior (CAPES) pelo financiamento da pesquisa de Doutorado que embasou o presente artigo, assim como às contribuições do Professor Dr. Marcos Antonio Bezerra Figueiredo (UFRPE), que nos conduziram ao Fórum Seca.

\section{Referências}

Abreu e Lima, M. do S. de. Revisitando o campo: lutas, organização, contradições - Pernambuco 1962-1987. Recife, Tese (Doutorado em História) - UFPE, 2003.
Amorim, L. O. do; Grisa, C. Combater a seca ou conviver com o semiárido? Fóruns e arenas de políticas públicas no semiárido brasileiro. Raízes, 38(2), 43-57, 2018. Disponí- 
vel em: http://raizes.revistas.ufcg.edu.br/index.php/raizes/ article/view/485/464

Assis, T. R. de P. Sociedade civil e a construção de políticas públicas na região semiárida brasileira: o caso do Programa Um Milhão de Cisternas Rurais (P1MC). Revista Politicas Públicas, 16(1), 179-189, 2012. Disponível em: http:// www.periodicoseletronicos.ufma.br/index.php/rppublica/ article/view/1189

Bordalo, C. A. Os caminhos da política: o sindicalismo rural e os movimentos de mulheres trabalhadoras rurais de Pernambuco. Rio de Janeiro, Dissertação (Mestrado em Ciências) - UFRRJ, 2011.

Bourdieu, P. Propos sur le champ politique. Lyon: Presses Universitaires de Lyon, 2000.

Bourdieu, P. Sobre o Estado. 1. ed. São Paulo: Companhia das Letras, 2014.

CONTAG - Confederação Nacional dos Trabalhadores na Agricultura. Diretrizes para a convivência com o semiárido: uma contribuição da sociedade civil para a construção de políticas públicas. Recife, março de 2013. Disponível em: http://www.contag.org.br/arquivos/portal/Diretrizes $\% 20$ para $\% 20 \mathrm{a} \% 20$ convivencia $\% 20$ com $\% 20 \mathrm{o} \% 20$ semiarido. pdf. Acesso em: maio 2020.

Cunha, L. H.; Paulino, J. S. Convivência com o semiárido: um novo paradigma para políticas públicas no Nordeste? In: Neves, D. P.; Gomes, R. A.; Leal, P. F. (Orgs.). Quadros e programas institucionais em políticas públicas. Campina Grande: EDUEPB, 2014. p. 27-58.

Dagnino, E. Confluência perversa, deslocamentos de sentido, crise discursiva. In: Grimson, A. (Ed.). La cultura en las crisis latino-americanas. Buenos Aires: CLACSO, Consejo Latinoamericano de Ciencias Sociales, 2004. p. 195-216.

Dagnino, E.; Teixeira, A. C. C. The participation of civil society in Lula's government. Journal of Politics in Latin America, 6(3), 39-66, 2014. Disponível em: https://journals. sub.uni-hamburg.de/giga/jpla/article/view/793/794.html

Declaração do Semiárido. Propostas da articulação no semiárido brasileiro para a convivência com o semiárido e combate à desertificação. Recife, 26 de novembro de 1999.
Diniz, P. C. O. Da experimentação social ao "experimentalismo institucional": trajetórias de relações entre Estado e sociedade civil. Experiências no semiárido. Campina Grande, Tese (Doutorado em Sociologia) - UFCG, UFPB, 2007.

Diniz, P. C. O.; Lima, J. R. T. de. Mobilização social e ação coletiva no semiárido brasileiro: convivência, agroecologia e sustentabilidade. Redes - Santa Cruz do Sul: Universidade de Santa Cruz do Sul, 22(2), 189-207, 2017. doi: 10.17058/ redes.v22i2.9353

Diniz, P. C. O.; Piraux, M. Das intervenções de combate à seca às ações de convivência com o semiárido: trajetória de "experimentalismo institucional" no semiárido brasileiro. Cadernos de Estudos Sociais, 26(2), 227-238, 2011. Disponível em: https://periodicos.fundaj.gov.br/CAD/article/ view/1457

Dossiê Fórum Seca. Fórum Pernambucano de enfrentamento à problemática da seca. Este dossiê registra destaques dos primeiros passos dados pelo Fórum Seca, o início dessa nova história escrita com a luta e a sabedoria os homens e mulheres comprometidos com a emancipação dos trabalhadores rurais do nosso Nordeste. Recife, junho de 1991.

Duque, G. "Conviver com a seca": contribuição da articulação do semiárido/ASA para o desenvolvimento sustentável. Desenvolvimento e Meio Ambiente, 17, 133-140, 2008. doi: 10.5380/dma.v17i0.13417

Duque, G. Água para o desenvolvimento rural: a ASA e os Programas P1MC e P1+2 - Desafios da participação sociedade civil - governo. In: Grisa, C.; Schneider, S. (Orgs.). Políticas Públicas de Desenvolvimento Rural no Brasil. Porto Alegre: Editora UFRGS, 2015. p. 201-216.

Fórum Nordeste. Ações permanentes para o desenvolvimento do nordeste/semiárido brasileiro. Propostas da sociedade civil. Recife, 10 a 13 de maio de 1993. CONTAG - Confederação Nacional dos Trabalhadores na Agricultura.

Funari, J. N. Um sertão de águas: mulheres camponesas e a reapropriação social da natureza no Pajeú. Recife, Dissertação (Mestrado em Desenvolvimento e Meio Ambiente) - UFPE, 2016.

Gohn, M. da G. Desafios dos movimentos sociais hoje no Brasil. SER Social, 15(3), 261-384, 2013. Disponível em: 
http://cressrn.org.br/files/arquivos/eILxHih2XPlto00h4990. pdf

I Seminário Pernambucano Seca, Implicações Políticas e Formas de Enfrentamento. Projeto Tecnologias Alternativas do Centro Josué de Castro; Polo Sindical de Serra Talhada, Comissão Pastoral da Terra; Grupo de Ecologia Humana da UFRPE; OXFAM. Camaragibe/PE, 27 a 30 de agosto de 1990.

Jalil, L. M. As flores e os frutos da luta. O significado da organização e da participação política para as mulheres trabalhadoras rurais. Rio de Janeiro, Tese (Doutorado em Ciências) - UFRRJ, 2013.

Malvezzi, R. Semiárido: uma visão holística. Brasília: Confea, 2007.

Muller, P.; Surel, Y. A análise das políticas públicas. 2. ed. Pelotas: EDUCAT, 2004.

Passador, C. S.; Passador, J. L. Apontamentos sobre as políticas públicas de combate à seca no Brasil: cisternas e cidadania? Cadernos Gestão Pública e Cidadania, 15(56), 65-86, 2010. doi: 10.12660/cgpc.v15n56.3203

Projeto Consolidação do Fórum Seca. Manoel Santos - FETAPE; Aristides Veras - CUT; Manoel Raimundo - CENTRU; Mauricio Aroucha-CAATINGA; Marcos Figueiredo - PTA/CJC. Recife, 12 de junho de 1991.

$1^{\circ}$ Encontro Seca - Implicações Políticas e Formas de Convivência. Polo Sindical do Sertão Central; Centro Josué de
Castro - Projeto Tecnologias Alternativas (Orgs.). Triunfo/ PE, 24 a 26 de outubro de 1989.

Relatório Histórico do Fórum Seca, 1989 a 1996. Recife, março, 1997.

Sieber, S. S. Entre novos paradigmas e velhas práticas: a convivência com o semiárido na agricultura familiar do sertão de Pernambuco (Brasil). 333 f. Campina Grande, Tese (Doutorado em Ciências Sociais) - UFCG, 2016.

Sieber, S. S.; Gomes, R. A. "Política e negociações" nos trilhos da convivência com o semiárido. Raízes, 38(2), 2342, 2018. Disponível em: http://raizes.revistas.ufcg.edu.br/ index.php/raizes/article/view/485/464

Silva, A. D. da. Da tecnologia alternativa à agroecologia: a contribuição das organizações populares de Pernambuco para a mobilização e ação em rede. In: Lima, J. R. T. de (Org.). Agroecologia e movimentos sociais. Recife: Bagaço, 2011. p. 39-68.

Silva, M. K.; Oliveira, G. de. L. A face oculta(da) dos movimentos sociais: trânsito institucional e intersecção Estado - Movimento: uma análise do movimento de economia solidária no Rio Grande do Sul. Sociologias, 13(28), 86-124, 2011. doi: 10.1590/S1517-45222011000300005

Silva, R. M. A. da. Entre o combate à seca e a convivência com o semiárido: políticas públicas e transição paradigmática. Revista Econômica do Nordeste, 38(3), 466-485, 2007. Disponível em: https://ren.emnuvens.com.br/ren/ article/view/539/427 